\title{
Application of Value Beliefs Norms Theory to the Energy Conservation Behaviour
}

\author{
Mustapha Harzallah Ibtissem \\ Higher Institute of Applied Studies in the Humanities of Tozeur \\ Rue Frahat Hached, Route de Nafta, 2200, Tunisia \\ Tel: 21-62-080-2312 E-mail: mustapha_ibtissem@yahoo.fr
}

\begin{abstract}
This paper tries to explain the conservation behaviour as one of the aspects of sustainable consumer behaviour. The theory of Values Beliefs Norms is chosen as the theoretical framework of this research. This theory discusses that the conservation behaviour is adopted owing to the activation of the personal norms by the values and the beliefs of individuals. A study of 703 individuals has been made in an attempt to test the model of this study. The data is analysed through the structural equations method. The results have enabled us to validate the VBN model in the Tunisian context.
\end{abstract}

Keywords: Sustainable behavior, Conservation behavior, Values, Beliefs, Norms

\section{Introduction}

The actual human development model is qualified as unsustainable because of the numerous economic, social and ecological crises experienced by humanity. For example, about half of the human effect on the environment has to do directly or indirectly, with production and consumption (Jongen and Meerdink, 1998). In this respect, production and consumption modes could be regarded as being the cause of these crises. In order to ensure balance at the economic, social and ecological levels both currently and in the future, the trend of sustainable development proposes a number of actions for its different actors.

The consumer's sustainable behaviour falls in this perspective, following an awareness of insufficient technological solutions and difficult implementation of a purely regulatory approach. The consumer's involvement in this development project reflects its evolving role. The latter has become more and more demanding and difficult to manipulate.

In effect, the consumer's sustainable behaviour manifests a new consumption culture, based on simplicity, the purchase and consumption of products and services. The latter respond to the consumer's basic needs without excessive environmental compromises nor affecting inter- and intra - generational equity (Mustapha, 2008, p79). In this context, the consumer can act in a sustainable way via his purchasing behaviour, including beginning voluntary simplicity, boycott, green purchase, fair purchase and so on. This behaviour can also be reflected through his habitual consumption of products or natural resources and waste management. Regarding sustainable behaviour, such consumption habits refer principally to the conservation behaviour (Mustapha, 2007, 2008). This behaviour is of particular interest to this paper. In fact a previous qualitative research allowed us to notice the connection between the Tunisian consumer's sustainable behaviour and his habitual consumption and usage of products or natural resources (Mustapha, 2007).

With reference to Stern et al.'s (1999) Values Beliefs Norms theory, this contribution intends to explore the extent to which the conservation behaviour is determined by norms. Its objectives are to mobilize the Values Beliefs Norms theory with the purpose of explaining the conservation behaviour as a kind of the consumer's sustainable behaviour. The paper is divided into three parts. First, the theory of Values Beliefs Norms (VBN) will be presented as well as a research hypothesis. Second, empirical study and results of analysis will be set out. Finally, results will be discussed, limits will be presented as well as future perspectives of research.

\section{Literary Review}

\subsection{Conservation behaviour}

Despite the efforts to sensitise the consumer to the dangers of waste, individual and collective habits live on. This is due to different evolutions which characterised the consumption society. The awareness of the danger of using up certain exhaustible resources, notably water, and the side -effects of the excessive consumption of other resources such as fossilised energies was at the origin of calls for conservation behaviour.

Theoretically speaking, the energy conservation is considered as a dimension of the conservation behaviour (Kaiser, 1998; Kaiser and Willson, 2004). From this perspective, the consumer tries to reduce the negative consequences of his consumption by adopting such good habits as the conservation of resources and for the maintenance of equipments using these resources or through the investment behaviour which includes the creation of thermal isolation of houses, the purchase of economic blenders and solar boards and so on.

Moreover, this behaviour requires that the consumer makes sacrifice at the expense of his own comfort and in favour of others interest. This makes the conservation behaviour a socially-responsible behaviour which 
integrates ethical, environmental and social preoccupations in the process of the consumer's choice (Webster, 1975).

The interest of the consumer's ecological and ethical behaviour manifests itself through the development of several research methods in marketing. We can mention examples like research trends in the environmental preoccupation which addresses the identification of the characteristics of the environmentally preoccupied consumer (Kinnear, Taylor and Ahmed, 1974), the conservation society which calls for de-consumption (Henion and Kinnear, 1976), green marketing which valorises the producer's engagement will (Peattie, 1992), ecological marketing valorising the consumer's will to self- involvement (Henion and Kinnear, 1986), much like the tendency to macro marketing which integrates macro-cultural dimensions in the study of consumer's behaviour (Van Dam and Apeldoorn, 1996). This theoretical richness gave birth to several models which allow explaining the adoption of ecological behaviours.

\subsection{The theory of Values Beliefs Norms}

According to Stern et al. (1999) and Stern (2000), the VBN is considered as the best to explain ecological behaviours such as ecological citizenship, political support and behaviours adhering to the private sphere. These assertions justify the recourse of this article to the VBN theory to explain the conservation behaviour.

The VBN theory is principally founded on Schwartz's (1977) theory of Norms Activation. The latter was one among the early theories of social psychology used to explain the environmental behaviour. It is strongly inspired by the theory of Altruistic Behaviour (Schwartz, 1968). The model of Altruistic Behaviour is linear. According to it, the social norms are adopted by the individual. The altruistic behaviour must have a positive /negative effect on the other members of community.

Consequently, actions without social outcomes cannot be studied through this model. The altruistic model is adopted if it corresponds to the individual's moral norms and has positive consequences on the others and if the individual takes the responsibility of the aftermath of the behaviour. The notion of responsibility is a key to the considered theory. It is the direct determinant in this behaviour. However, it is the personal norms which play a central role within the framework of the theory of Norms Activation (Schwartz, 1977). The individual adopts altruistic behaviours out of a feeling of moral obligation. Furthermore, the personal norms are determined by the individual's awareness of the positive consequences of the resulting acts and responsibilities. These two variables directly affect the behaviour.

Schwartz's model insists that norms activation is more likely when the actor has two types of beliefs. First, the acting individual should be aware of the consequences of his act towards the subject of norm (A.C). Then, the individual has to feel responsible for causing or preventing these consequences (AR) (Bleamey, 1998, p48). However, if the individual perceives that his respect of norms might seriously harm his personal interest, he adopts defensive strategies. Then, he can either reject the consequences of the behaviour or his own responsibility in order to neutralize the norm (Schwartz, 1977). Besides, the model of the norm activation proved its efficacy for the study of several ecological behaviours: the important change in environmental attitudes (Heberlein, 1972), the emergence of an environmental ethic (Vandenbergh, 2005), the explanation of the individual consumption of energy (Black et al, 1985) and so on.

The VBN model is tested in several studies. Some authors limit themselves to testing a few sub-sections of the model (Kaiser, Hubner and Bogner, 2005; Nordlund and Garville, 2003). Others tested the model as a whole (Steg et al., 2005). The explanatory power of VBN model diminishes when the behaviour has a higher monetary value. For example, this happens when consumers pay more to buy sustainable products. It also diminishes when it is time-consuming and difficult. This occurs, for example, when people use public transport. Steg et al. (2005) relate this back to the fact that relatively costly behaviours are less connected to personal norms than less costly ones, e.g. the acceptance of energy politics.

\subsection{The model of study and introduction of variables}

The VBN theory assumes that the pro-environmental behaviour is traced back to a chain of causes relating a chain of five variables. These causality relations turn central elements of personality and relatively stable structures of belief into beliefs much more oriented towards the human being's relationship to the environment (NPE), their consequences (A.C) and the individual's responsibility for corrective actions (Stern, 2000, p. 413). The VBN model is presented in a linear way linking three levels of analysis: personal values, beliefs, and norms. The extreme end of this chain of causality makes reference to values.

Human values have already been studied by a number of researchers including psychologists and sociologists (Kahle, 1983; Rokeach, 1973). They influence almost every phenomenon studied in social sciences (Valette-Florence, 1994, p. 47). Moreover, they reflect one facet of the individual's personality. Being abstract principles, they mirror the concept of the self and serve as standards for the individual's behaviour across situations and in time.

This study distinguishes two types of values: social and environmental. Social values represent the individual's relation to oneself, inside groups and others (Schwartz, 1994); whereas environmental values reflect the human 
being's relation to the natural environment (Thompson and Barton, 1994). Both types of values are subject to numerous classifications. In this article, we consider Schwartz's typology as being pertinent to assessing social values. Schwartz's list of values is validated and applied to various cultures. These values play an important role in explaining an environmentally friendly behaviour (Duong and Robert-Demontrond, 2004; Stern et al., 1999; Steg et al., 2005). Of particular interest is the bi-dimensional axis: altruism and egoism. In fact, this axis is often used to structure the motives which impact the preparedness to a collective action (Stern and Dietz, 1994; Stern et al., 1993). The conservation behaviour can be considered as a collective action. In this respect, a positive correlation is always identified between altruistic motives and pro-environmental behaviour (Stern and Dietz, 1994; Grunert et Juhl, 1995; Stern, Dietz, Kalof and Guagnano, 1995; Stern, 2000; Nordlund and Garvill, 2003). As to egoistic values, they are traditionally oppositional to the adoption of pro-environmental behaviours.

The VBN theory postulates that values have an influence on the awareness of consequences (AC). Hence, we propose that:

H1: The more a person adheres to altruistic values, the more he becomes aware of the consequences of energy conservation.

H2: The more a person adheres to egoistic values, the more he becomes aware of the consequences of energy conservation.

In the context of environmental values, the typology of values outlined by Thompson and Barton (1994) is adopted. Thompson and Barton (1994) distinguish between anthropocentric values and ecocentric ones. Anthropocentric values are developed by an anthropocentred vision based on the idea of the primacy and dominance of Man on nature. He can take and exploit whatsoever resource. In addition, the human system functions independently of nature. The anthropocentric perception may even lead to an excessive exploitation of nature. The anthropocentric logic admits that the pollution and exhaustion of natural resources are the natural consequences of economic progress (Kaufman and Franz, 1993).

In counterpart, ecocentric values identify Man as part of a whole, i.e .nature, submissive to all natural laws in the same way as whatever entity on earth (Kaufman and Franz, 1993). This approach pre-supposes the respect of nature and suggests that man has to learn to live in harmony with the environment. "The ecocentric individual valorises nature and, in consequence, considers that the latter deserves to be preserved for the sake of its intrinsic values" (Thompson and Barton, 1994, p. 150). In this respect, the consumer believing in ecocentric values cares for the environment independently of the interests coming out of its preservation to the determinant of the quality of his life or of the economy.

According to the VBN model, we propose that:

H1.3: The more a person agrees to anthropocentric values, the more he becomes aware of the consequences of energy conservation

H1.4: The more a person agrees to ecocentric values, the more he becomes aware of the consequences of energy conservation.

In addition, Nordlund and Garvill (2003) consider that values directly affect personal norms and indirectly influence the latter through beliefs. They have found out that the more important self-transcending and ecocentric values are, the more committed individuals are to the adoption of an ecological behaviour. Thus, values, both ecocentric and transcendent, affect indirectly and positively personal norms. Consequently, we suggest the following hypotheses:

H2.1: The more a person agrees to altruistic values, the more morally engaged he feels to conserve energy.

H2.2: The more a person agrees to egoistic values, the more he does not feel morally engaged to conserve energy.

H2.3: The more a person agrees to anthropocentric values, the more morally engaged he feels to conserve energy.

H2.4: The more a person agrees to ecocentric values, the more morally obliged he feels to conserve energy.

The second level of causality chain in the VBN model makes reference to beliefs. Three variables are at work at this level. The first variable is concerned with the perception of the relationship of Man with nature. It corresponds to the view that the biosphere is fragile and that its status is influenced by Man's deeds. This corresponds to Dunlap et al.'s (2000) new environmental and ecological paradigm (NEP). The adoption of NEP determines the beliefs regarding the negative consequences of this behaviour (AC).

The AC determines the individual perceived capacity to lessen the danger of the consequences of these behaviours. As a result, the individual assumes the responsibility for accomplishing the behaviour (AR). This will create a feeling of obligation to act in order to protect the environment in terms of personal norms.

Accordingly, we propose that:

H3: The awareness of consequences positively affects the attribution of responsibility. 
The VBN theory proposes that personal norms are enhanced by the attribution of responsibility. Therefore, we suggest the following hypothesis:

H4: The attribution of responsibility both directly and positively affects personal norms.

Personal norms are the closest determinant to behaviour. They are, in fact, the ultimate preachers of action representing the person's obligation to adopt a pro-environmental behaviour.

Traditionally, there is a distinction between two types of norms: social and personal (Stern, 2005). Social norms are the result of a societal life. Actually, the fact of living in a society, of finding one self in a given cultural milieu, of being accompanied by one or several persons, may result in the individual's submission to a certain social influence. This influence plays a lot of functions, among which is the creation of norms, that is common frames of reference which form a group's cohesion (Accabat and Laurenti, 2006).

As far as personal norms are concerned, they represent the sentiment of moral obligation to adopt certain behaviour. They may provide internalized social norms or norms deriving from values. In this context, the adoption of a pro-social behaviour depends on the enhancement of self-transcendent values. Personal norms are, thus, distinct from social ones (Schwartz, 1977, p. 23). Indeed, sanctions and rewards, relating to personal norms, are attached to the concept of self. This way, conformism to personal expectation begets self-esteem, pride, security and every other favourable auto-evaluation. Contrarily, non-conformism to personal norms induces the loss of self-esteem, auto-depreciation and a sentiment of guilt (Batson, 1987; Tangney, 1992).

On the ground of VBN theory, we propose that:

H5: Norms exercise a direct positive effect on the conservation behaviour.

\section{Methodology and Results}

Considering that the entire measurements of the model variables are developed within western contexts, different from this study's field work, a number of interviews are conducted in order to adapt and contextualize these scales. In an attempt to simplify the phase of data collection, this research is limited to the study of residential energy conservation behaviour. Two experts of energy are contacted in order to adapt the scale of measuring this behaviour and ensure its facial validity. Besides, specialists in English and Arabic have helped with the translation of the different scales of measurement. Used scales figure in the appendix 1.

An investigation involving 203 individuals is conducted, in order to purify and verify the validity and reliability of the different scales used. After having purified the questionnaire, about 703 individuals are interviewed. Given that we are at a confirmation phase, we have tried to respect the condition of 'the number of observations multiplied by 15". The chosen method of sampling is that of quota. The questionnaire has been auto-administered in order to reduce the impact of social desirability. Both investigations have taken place in January, February and March 2008. The objective of this final study has been, at an initial stage, to verify the validity and reliability of scales of measurement, and at a later stage, to test the postulated hypotheses. In this regard, the method of structural equation is adopted.

\subsection{Results relative to the psychometric quality the scales of measurement}

The data collected during the second investigation has been the subject of analyses via the structural equation modelling. The values calculated of the $\rho$ of the convergent validity $(\rho v c)$ of different scales of measurement show that the levels of their internal coherence are fairly satisfying. Similarly, the $\rho v c$ values demonstrate that the convergent validity of different scales has been well-verified (see Appendix 2 table 1)

Despite the verification of univariant normality, the test of multinormality has indicated a significant non-normality through the Mardia coefficient equal to 12,544 with a $t$ of 2.8 . Bootstrap procedure has been followed in order to estimate the global model. First a bootstrap of 2000 samples has been conducted to generate Bollen Stine's $p$. The latter shows that this model is fair $(\mathrm{p}=0.000)$. Second, the bootstrap procedure with 250 samples randomly selected is employed. The Bias exam shows that results are significantly stable. In this way, the interpretation of the indices generated by the direct procedure could be carried out.

The exam of fit indices of measurement model shows a fair level of fit modelling which has been suggested to the data collected (Appendix 2, table 2). Absolute indices GFI and AGFI provide values superior to the required level (respectively 0.926 and 0.915 ).

The RMR equals 0.046. Likewise, the comparison indices show that the modelling of global measurement is close to saturated modelling that is the TLI and CFI indices show values superior to 0.95 (TLI $=0.978$ and CFI $=0.978)$. The parsimony indices are additionally inferior to the indices of saturated modelling.

\subsection{Results of the Hypothetical test:}

The structural relations in the model which has been developed in the literature review are established between eight variables of which four are exogenous and four are endogenous. The analysis of the structural modelling indicates a high goodness of fit of data (Appendix 2, table3).

The global modelling presents the chi-square of 1278.610 for a dof $=721$. Despite the significant chi-square of the test $(\mathrm{p}<0.05)$, the remaining absolute fit indices are satisfying $(\mathrm{GFI}=0.916, \mathrm{AGFI}=0.904, \mathrm{RMR}<0.1$; 
RMSEA <0.05). Furthermore, the fit indices, compared to the saturated model, are all superior to 0.9 (TLI $=$ 0.965 , CFI $=0.968$ ). These indices show that the proposed model adjusts to the variance-covariance matrix better than the adjustment of the free model.

Table 4 (see Appendix 2) displays the regression weights, the standardised regression weights and the squared correlation of the relations suggested in the model. Out of all the proposed relations in the model, four seem insignificant. The remainder of the hypothetical relations has been verified through $\alpha$ largely superior to $+/-1.96$.

The anthropocentric and altruistic values significantly affect the beliefs in the consequences of the individual's energy conservation (respectively, $\mathrm{t}=7.595 \mathrm{p}<0.001 ; \mathrm{t}=3.947, \mathrm{p}<0.001$ ). Thus, the more a person adheres to anthropocentric and altruistic values, the more sensitive he becomes of the consequences of energy conservation (respectively, $\gamma=0.379 ; \gamma=0.221$ ). Accordingly, the hypotheses H11 and H13 are accepted.

Egoistic and econcentric values have no significant impact on the awareness of consequences (respectively $\mathrm{t}=$ $-1.721, \mathrm{p}>0.05 ; \mathrm{t}=1.923, \mathrm{p}>0.05)$. Hence, the hypotheses H1.2 and H1.4 are rejected. In addition, the more sensitive a person is of the consequences of energy conservation, the more responsible he is for resolving problems linked to the energy consumption $(\beta=0.465 ; \mathrm{t}=12.198, \mathrm{p}<0.001)$. This still confirms the hypothesis H3.

In turn, personal norms are positively influenced by the consumer's adherence to anthropocentric values $(\gamma=$ $0.189)$, altruistic $(\gamma=0.270)$ which in turn confirms hypotheses H2.1 and H2.3. Besides, the consumer who assumes the responsibility for preserving energy $(\beta=0.240)$ feels morally obliged to adopt this behaviour. This confirms hypothesis H4. Nevertheless, analyses show that egoistic and ecocentric values do not have any impact on the individual feeling of moral obligation to preserve energy (respectively $\mathrm{t}=-1.093, \mathrm{p}>0.1 ; \mathrm{t}=0.266$, $\mathrm{p}>0.5$ ). This rejects the hypotheses $\mathrm{H} 2.2$ and $\mathrm{H} 2.4$.

SMC values signal that $58 \%$ of the variation of the awareness of consequences is inexplicable. Moreover, $66 \%$ of the variation of the attribution of responsibility remains without explanation. The proposed model works towards explaining the major portion of personal norms (64\%). Three variables contribute to explaining personal norms such as the attribution of responsibility, altruistic and anthropocentric values. The model in question explains solely 0.058 of the variance of the conservation behaviour through personal norms with respect to these consequences, 0.942 of the variance of the conservation behaviour find explanation in other variables.

\section{Discussion of results}

Confirmatory factor analysis conducted on the involved model outlines the distinction between environmental values and self-transcendent values. The chosen four values in this study prove fairly distinctive from each other. As such, despite the strong correlation between the effects of altruism and anthropocentrism, they provide a distinguished validity. Likewise, the noticeable variables, used to measure egoism and ecocentrism, solely reflect their correspondent latent variables clearly. This result contrasts with the results of other several studies which have failed to distinguish between environmental and self-transcendent values through the method of principal component analysis (Karp, 1996). Similarly, Stern (1998) has not managed to separate the three variables during the AFC, although he has reached acceptable coefficients of reliability for these values within his first analyses.

This result converges with that of Nordlund and Garvill (2003). The latter have been able to distinguish between self-transcendent, anthropocentric and ecocentric values. In turn, De Groot (2008) affirms the finding that self-transcendent and environmental values are universally distinct. These values prove to be distinctive in five European countries.

The identification of environmental, altruistic and egoistic values in the Tunisian context reflects the development of an environmental awareness. The latter has allowed making difference between the valorisation of the environment both for its own sake and for the sake of the human being.

In addition to this, the test of the direct effects demonstrates that altruistic and anthropocentric values positively affect beliefs having to do with the awareness of consequences and personal norms. These connections have been checked within various studies conducted in the vein of pro-environmental behaviour and conservation (Stern et al., 1999; Steg et al., 2005; Nordlund and Garvill, 2003; Abrahamse, 2007, De Groot, 2008).

Ecocentric values are, on the contrary, incapable to influence the awareness of consequences and personal norms. These results diverge according to previous studies, although partially, confirming those of De Groot (2008). Despite the increasing awareness of the importance of the environment, ecocentric values appear to have no impact on the Tunisian consumer. This might be due to the idea that, even though certain consumers valorise nature for its own sake, they consider that the task of environmental protection essentially depends on the government and enterprises (Mustapha, 2007). As such, these ecocentric values do not enhance any sentiment of moral obligation.

As the selfish values, the involved results show that this variable has a complex role. This way, egoism does not have any negative influence on the awareness of consequences as it has been expected. It has proved ineffective. Though the results of this study reinforce those of De Groot (2008), they oppose the findings of several studies (Steg et al., 2005; Stern et al., 1999; Abrahamse, 2007). 
Moreover, selfishness does not either affect personal norms. This could be because of the utilitarian character of such values. Consequently, a selfish individual would be less involved in the protection of the environment if there is an interference with other values centred on the human being such as the quality of life

The divergence that we have deduced between the present results and previous studies might be explained with reference to the cultural specificity of the country understudy. This specificity has an impact on the types of the enhanced values and so it does on the scope of their effects.

The attribution of responsibility positively influences personal norms. This influence is relatively important. As such, the more responsibility a person assumes for resolving problems related to energy, the more dutiful he feels to preserving this resource $(\gamma$ stand. $=0.663, \mathrm{p}<0.001)$. This result is in line with the hypotheses of Norms Activation Theory. According to the latter, norms are in part enhanced by the beliefs pertinent to the attribution of responsibility. De Groot (2008) has managed to verify this relation vis à vis the different behaviours that she has investigated on several occasions. Likewise, Steg et al.(2005), Kaiser et al.(2005), Abrahamse (2007), Stern et al.(1999), have all confirmed a significantly positive influence of the attribution of responsibility on the personal norms.

The awareness of consequences has been associated with an auto-attribution of responsibility. A high level of awareness of the consequences has been associated with an auto- attribution of responsibility for the problem and its resolution. This result converges with several other studies (Gärling et al., 2003; Stern et al., 1999; Kaiser et al., 2005; Steg et al., 2005; Abrahamse, 2007; Black, et al., 1985; and De Groot, 2008).

The behaviour of energy conservation is positively and significantly connected to personal norms. This finding conforms to the VBN theory and that of norms activation. Both theories postulate that personal norms represent the determinant which is the closest to behaviour. Several studies which have tested these theories have deduced a significant relationship between these two variables (Nordlund and Garvill, 2003; Steg et al., 2005, De Groot, 2008; Stern et al., 1999, Kaiser et al., 2005; Gärling et al., 2003). Contrarily, Abrahamse (2007) has not reached a significant effect of norms on the behaviour of the conservation of residential energy.

Furthermore, the results have demonstrated that the entirely of the linear effects of considered conceptual model contributes to explaining only $5.8 \%$ of the variance of the conservation behaviour. Abrahamse (2007) has reached similar values. This result implies that other variables and relations must be taken into consideration to explain the conservation behaviour.

The regression coefficient is relatively weak. This could be explained with reference the high cost of the behaviour of energy conservation. Lindenberg and Steg (2006) postulate that energy conservation is more connected to the perception of the capacity of the consumer to adopt this behaviour and to his attitude towards it. The variables related to the environment play a trivial role.

\section{Contributions of the study, Limitations and Potential research Projects}

This research allows us to make clarifications in an emergent research field. More precisely, it provides a contribution to the theoretical framework of the consumer's sustainable behaviours involving many aspects of research such as the theoretical, methodological, political and managerial ones.

Theoretically speaking, this research provides two contributions. It both allows to develop the acquired knowledge of certain concepts and variables and to study under-researched subjects. Although the effect of social values notably altruistic and egoist ones has been well-researched in the field of sustainable behaviour (Dietz et al., 2005), it has been under-investigated in the field of energy conservation (Abrahamse, 2007; de Groot, 2008; Steg et al., 2005). Likewise, the environmental values, notably Thompson and Barton's (1994) distinction between anthropocentric and ecocentric values, are barely used in exploring pro-environmental behaviours, particularly, in the area of energy conservation. The results of this study have allowed to accumulate knowledge of the impacts of altruism, egoism, anthropocentrism and ecocentrism related to the behaviour of energy conservation.

The methodological contributions of this paper are principally in accordance with the contextualisation of validation of a certain number of scales.

First of all, the recourse to experts in the domain of energy represents an important step in contextualizing the scales and ensuring their content validity. Indeed, it proves to be absurd to adopt, in integral terms, certain scales originating from a western context, mainly, Scandinavian.

In addition, this paper consolidates the research results which show that the method of altruistic / egoistic values is quite applicable to the Tunisian context. The other methodological achievement resides in validating the typology of environmental values which has been set out by Thompson and Barton (1994). The psychometric analysis reveals a satisfactory level of reliability as well as a solid validity, both divergent from and convergent with this scale.

The practical dimensions of this paper mainly consist in orienting such public establishments as the Tunisian Company for Electricity and Gas, the National Company for the Exploitation and Distribution of Water and the institutional bodies which are interested in the environment and / or energy. 
This paper has shown that these agents could act upon certain variables. For instance, it appears that altruistic and anthropocentric values play an important role. They have varying degrees of influence on the personal norms, the awareness of consequences and the attribution of responsibility. Therefore, it is important to promote these values in educational institutions and through campaigns of consciousness-raising. In this context, pro-environmental behaviours and actions should be highly valued. Moreover, the refutation to neglecting values and norms by society is likely to maintain altruism and anthropocentrism through intimidation which triggers such emotions as shame or guilt (Tangney et al., 2007). The consumer's awareness of the harmful effects of the excessive consumption of energy acts upon the beliefs in the self- attribution of responsibility. This way, it would be necessary to shape and inform the consumer as to the environmental damages caused by the consumption of natural resources.

Given that the conservation behaviour could be largely determined by utilitarian considerations, it would be pertinent to motivate the consumer by making him aware of raising his consciousness of the benefits of the energy conservation with regard to his purchasing power and the national economy. The consumer will pay attention to his behaviour if he gets informed about the gains of energy e.g water. From this perspective, the government should spread information about the high cost of energy. In a similar way, the consumer should be sufficiently informed about the side-effects of his behaviour on the environment. The government and the organisms which have environmental preoccupations should require the producers to have on the equipment of their merchandise labels that contain information about the consumption of energy and the issue of greenhouse gas emissions.

In addition to this, it would be interesting to develop in the citizen consumer a feeling of responsibility for the problems of energy. As has been suggested by the model, this responsibility could be achieved thanks to an awareness of the consequences of the adopted habits. To this level, it would be of interest to communicate the equivalent of those habits and actions in terms of $\mathrm{CO} 2$, that is, environmental cost, personal cost, and the governmental subsidy or the collective cost. These strategies might, as a consequence, urge the consumer to pay attention to his consumption of energy.

In parallel to this, the citizen himself, as an essential agent in this process, should be aware of these stakes and feel responsible for this issue so that the sustainable development would really be at the core of the public strategies. The citizen should be formed and informed, know the essence of the sustainable development, grasp the importance of the interactions between economic, social and environmental domains and assess the consequences of his gestures and daily behaviour, in order to achieve his role effectively and persuasively. In this way, the government assumes a fundamental responsibility that consists in educating and training the consumer.

Education and information serve as stimuli for the fostering of critical minds and the enforcement of an ethic respectful to and responsible for the others as a way of creating options and choice. In consequence, it will be possible for the consumer to enjoy an adequate power. Media represent a principal vector of informing and educating citizen consumers.

However, this paper has a number of limitations. As a matter of fact, the limitation of study of the behaviour of the energy conservation involves the external validity of this work. In the same way, the recourse to self-report in order to evaluate the conservation behaviour limits this research. The increasing need for reducing the consumption of natural resources promotes the development of the theory about this issue. It would be possible to enrich this model in order to maximize the variance involving the conservation behaviour. It would equally be interesting to examine the contribution of the considered efficacy habits, knowledge and contextual variables such as price and publicity to explain the conservation behaviour.

Other researchers may re-examine certain findings which are in conflict with previous studies. Thus, it would be of interest to find out the reason why ecocentric and egoistic values are not taken into account in the context of this research. Eventually, it would be worthy that potential projects investigate the reasons for which certain values operate in different ways, depending on the context.

\section{References}

Abrahamse W. (2007). Energy conservation through behavioral change: Examining the effectiveness of a tailor-made approach, Doctoral dissertation. Groningen University.

Accabat A. \& Laurenti V. (2006). Sensibilisation du grand public à l'environnement: Comment mieux comprendre les individus? 9èmes rencontres régionales d'éducation à l'environnement, Languedoc-Roussillon 08 décembre, 27.

Biel A. \& Thøgersen J. (2007). Activation of social norms in social dilemmas: A review of the evidence and reflections on the implications for environmental behaviour. Journal of economic psychology, 28, 93-112.

Black, J., Stern P. C. \& Elworth J. (1985). Personal and contextual influences on household energy adaptations. Journal of Applied Psychology. 70, 1, 3-21.

Blamey R. (1998). Analysis contingent valuation and the activation of environmental norms. Ecological 
Economics, 24, 47-72.

De Groot J. (2008). Mean or green? Value orientations, morality and prosocial behaviour. Doctoral dissertation,University of Groningen.

Dietz T., Fitzgerald A., \& Shwom R. (2005). Environmental values. Annual Review of Environment and Resources, 30, 335-372.

Haribey J.M. (1998). Le développement soutenable, Paris, Economica.

Heberlein T.A. (1972). The land ethic realized: Some social psychological explanations for changing environmental attitudes. Journal of Social Issues 28, 4, 79-87.

Henion K.E., Kinnear T.C. (Eds.). (1976). Ecological Marketing. Chicago : American Marketing Association.

Jongen W. \& Meerdink G. (1998). Food Product Innovation: How to Link Sustainability and the Market. Wageningen Agricultural University.

Karp, D. G. (1996). Values and their effects on pro-environmental behaviour. Environment and Behavior, 28, 111-133.

Kaiser F. (1998). A general measure of ecological behaviour. Journal of applied social psychology, 28, 5, 395-422.

Kaiser F.G \& Wilson M. (2004). Goal-directed conservation behavior: the specific composition of a general performance, Personality and individual differences, 36, 1531-1544.

Kaiser F.G., Hubner G. \& Bogner F.X. (2005). Contrasting the theory of planned behavior with the value-belief-norm model in explaining conservation behaviour. Journal of applied social psychology, 35, 10, 2150-2170.

Kaufmanm, D.G. \& Franz C.M. (1993). Biosphere 2000: Protecting Our Global Environment. New York: Harper Collins.

Kinnear T.C., Taylor J.R., Ahmed S.A. (1974). Ecologically Concerned Consumers: Who Are They ?. Journal of Marketing, 38, 2, 20-24.

Kahle L.R. (1983), Social values and social change: Adaptation to life in America, New York, Praeger cité dans Kahle L.R et Kennedy P. (1989). Using List Of Values (LOV) to understand consumers, The Journal of Consumer Marketing, 6, 3.

Lindenberg, S., \& Steg, L. (2006). Normative, Gain and Hedonic Goal-Frames Guiding Environmental Behavior. Journal of Social Issues, 65, 1, 117 -137.

Mustapha I. (2008). Le comportement durable du consommateur: Application au secteur de l'énergie résidentielle. Unpublished doctoral dissertation, Paul Cézanne University, France.

Mustapha I. (2007). Vers une meilleure compréhension de la consommation durable : étude exploratoire, colloque ATSG, April.

Nordlund A.M. \& Garvill J. (2003). Effects of values, problem awareness, and personal norm on willingness to reduce personal car use, Journal of environmental psychology, 23, 339-347.

Peattie K. (1995). Environmental Marketing Management. Meeting the Green Challenge. London: Pitman Publishing, 309 pages.

Rokeach M. (1973). Nature of human values, New York: Free Press, cité dans Gibbins K. et Walker I. (1993) Multiple interpretation of Rokeach Value Survey, The journal of social psychology, 133, 6, 797-805.

Schwartz S. (1977). Normative Influences on Altruism. Advances in Experimental Social Psychology. 10, 222-279.

Schwartz, R. A. (1968). Corporate Philanthropic Contributions. The Journal of Finance, Vol 23-3, 479-497. In Boulanger P. M. and Lussis B. (2005). Les barrières internes à l'efficacité énergétique l'apport de la psychologie sociale, séminaires Energie.

Schwartz S.H. (1994). Are there universal aspects in the structure and contents of human values?. Journal of social issues, 50, 4, 19-45.

Steg L., Dreijerink L. and Abrahamse W. (2005). Factors influencing the acceptability of energy policies: A test of VBN theory, Journal of environmental psychology, 25, 415-425.

Stern P.C, Dietz T., Abel T., Guagnano G.A. and Kalofl L. (1999). A value-belief-norm theory of support for social movements: The case of environmentalism, Research in human ecology, 6, 2, 81-97.

Stern, P. C., Dietz, T., and Guagnano, G. A. (1995). The new ecological paradigm in social-psychological context. Environment and Behavior, 27, 723-753.

Stern, P. C. and Dietz, T. (1994). The value basis of environmental concern. Journal of Social Issues, 50, 65-84. 
Stern P.C., Dietz T. and Kalof L. (1993). Value orientations, gender, and environmental concern, Environment and Behavior, 25, 322-348.

Stern P.C. (2000). Towards a coherent theory of environmentally significant behaviour, Journal of social issues, $56,3,407-424$

Stern P.C. (2005). Understanding Individuals' Environmentally Significant Behavior, ELR news and analysis, 35, 10785-10790.Stern P.C., (1992), Psychological dimensions of global environmental change, Annual review of psychology, 43, 269-302.

Tangney J. P., Stuewig J. and Mashek D. J. (2007). Moral emotions and moral behaviour, Annual Review of Psychology, 58, 345-372.

Thompson S.C.G. and Barton M.A. (1994). Ecocentric and anthropocentric attitudes toward the environment. Journal of environmental psychology, 14, 149-157.

Valette-Florence P. (1994). Les styles de vie : Bilan, critique et perspectives. Paris, Nathan.

Van Dam Y.K., Apeldoorn P.A.C. (1996). Sustainable Marketing. Journal of Macromarketing, 16, fall, 45-56.

Vandenbergh M.P. (2005). Order without social norms: How personal norm activation can protect the environment. Northwestern University Law Review, 99, 3, 1101-1166.

Webster F.E. (1975). Determining the characteristics of the socially conscious consumer. Journal of consumer research, 2, 188-196.

Appendix 1: Measurement scales

\section{Scale of energy conservation}

I leave the electric machines on standby mode

I switch off the light when I leave the room

In the winter, I leave the windows open for long periods of time to let in fresh air

I prefer to shower rather than to take a bath

In the winter, I keep the heat on so that I do not have to wear a sweater

I use the maximum of natural light

In summer, I make use of the air-conditioned and / or the fan

I wait until I have a full load before doing my laundry

I wash dirty clothes without prewashing

\section{Altruistic values}

Helpfulness: work for the welfare of the others

Equality: provide equal opportunities for all

Social justice: pay attention to the weak, correction of the injustice

A world of peace without war or conflict

Egoistic values

Authority: the right to lead or to command

Social power: the right to control or dominate the others

Wealth: the possession of good materials and money

Influence: the possession of impact on people and events

Awareness of consequences

Climate change will be a problem for other species of plants and animals,

Energy savings help reduce global warming

Environmental quality will improve if we use less energy

Do you think that climate change will be a very serious problem for the country as a whole

Energy saving will be advantageous for our country

Saving energy will be advantageous for me and for my family

The climatic change is a serious problem that affects you personally

\section{Attribution of responsibility}

I am jointly responsible for the energy problems

I feel jointly responsible for the exhaustion of energy sources 
I feel jointly responsible for global warming

My contribution to the energy problems is negligible

Not only the government and industry are responsible for high energy consumption levels, but me too

In principle, individuals at their own cannot contribute to the reduction of energy problems

\section{Personal norms}

I feel personally obliged to save as much energy as possible

I feel morally obliged to save energy, regardless of what others do

People like me should do everything they can to reduce energy use

I feel guilty when I waste energy

If I would buy a new washing machine, I would feel morally obliged to buy an energy efficient one

I feel guilty when I buy vegetables and fruit from distant countries when their import causes energy consumption I feel obliged to bear the environment and nature in mind in my daily behaviour

I would be a better person if I saved energy

\section{Anthropocentrism}

The worst thing about the loss of the rain forest is that it will restrict the development of new medicines

The thing that concerns me most about deforestation is that there will not be enough lumber for future generations

It bothers me that humans are running out of their supply of oil

One of the best things about recycling is that it saves money

The most important reason for conservation is human survival

Nature is important because of what it can contribute to the pleasure and welfare of humans

We need to preserve resources to maintain a high quality of life can be preserved

One of the most important reasons to conserve is to ensure a continued high standard of living

Continued land development is a good idea as long as a high quality of life can be preserved

\section{Ecocentrism}

One of the worst things about overpopulation is that many natural areas are getting destroyed for development

I can enjoy spending time in natural settings just for the sake of being out in nature

Sometimes it makes me sad to see forests cleared for agriculture

I prefer wildlife reserves to zoos

I need time in nature to be happy

Sometimes when I am unhappy I find comfort in nature

It makes me sad to see natural environments destroyed

Nature is valuable for its own sake

Being out in nature is a great stress reducer for me

One of the most important reasons to conserve is to preserve wild areas

Sometimes animals seem almost human to me

Human are as much a part of the ecosystem as other animals

\section{Appendix 2}

Table 1 . Internal reliability and convergent validity

\begin{tabular}{|l|c|c|}
\hline \multicolumn{1}{|c|}{ Variables } & $\rho \xi$ & $\rho v c$ \\
\hline Energy conservation & 0.915 & 0.629 \\
\hline Altruistic values & 0.858 & 0.601 \\
\hline Egoistic values & 0.875 & 0.638 \\
\hline Anthropocentrism & 0.867 & 0.671 \\
\hline Ecocentrism & 0.888 & 0.666 \\
\hline Awareness of consequences & 0.829 & 0.606 \\
\hline Attribution of responsibility & 0.836 & 0.561 \\
\hline Personal norms & 0.895 & 0.631 \\
\hline
\end{tabular}


Table 2. Fit indices of measurement model

\begin{tabular}{|c|c|c|c|c|l|c|c|c|c|}
\hline \multicolumn{1}{|c|}{$\mathrm{X}^{2}$} & $\mathrm{X}^{2} / \mathrm{ddl}$ & GFI & AGFI & RMR & RMSEA & TLI & CFI & BIC & CAIC \\
\hline $\begin{array}{l}1091.566 \\
\mathrm{ddl}=711 \\
\mathrm{p}=.000\end{array}$ & 1.535 & 0.926 & 0.915 & 0.047 & $\begin{array}{l}0.028 \\
(0.025 ;\end{array}$ & 0.976 & 0.978 & $\begin{array}{c}1802.474 \\
\text { Ms } \\
(5348.116)\end{array}$ & $\begin{array}{c}1911.474 \\
\text { Ms } \\
(6168.116)\end{array}$ \\
\hline
\end{tabular}

Table 3. Fit indices of direct effects of the structural model

\begin{tabular}{|c|c|c|c|c|c|c|c|c|c|}
\hline$\overline{X^{2}}$ & $\mathrm{X}^{2} / \mathrm{ddl}$ & $\overline{\text { GFI }}$ & $\overline{\text { AGFI }}$ & RMR & RMSEA & TLI & $\overline{\mathrm{CFI}}$ & $\mathrm{BIC}$ & $\overline{\text { CAIC }}$ \\
\hline $\begin{array}{c}1278.610 \\
\mathrm{ddl}=721 \\
\mathrm{p}=.000\end{array}$ & 1.773 & 0.916 & 0.904 & 0.092 & $\begin{array}{c}0.034 \\
(0.031 ; \\
0.037)\end{array}$ & 0.965 & 0.968 & $\begin{array}{c}1924.297 \\
\text { Ms } \\
(5348.116)\end{array}$ & $\begin{array}{c}2023.297 \\
\text { Ms } \\
(6168.116)\end{array}$ \\
\hline
\end{tabular}

Table 4. Results of the test of direct effects

\begin{tabular}{|c|c|c|c|c|c|c|}
\hline Factor & Relations & $\begin{array}{c}\text { Regression } \\
\text { weight }\end{array}$ & $\mathrm{t}$ & $\mathrm{P}$ & $\begin{array}{c}\text { Standardized } \\
\text { Regression } \\
\text { weight }\end{array}$ & $\begin{array}{c}\text { Squared } \\
\text { multiple } \\
\text { correlations }\end{array}$ \\
\hline \multirow{4}{*}{$\begin{array}{l}\text { Awareness of } \\
\text { consequences }(\mathrm{AC})\end{array}$} & $<--\quad$ ecocentrism & 0.067 & 1.923 &, $054 *$ & 0,068 & \multirow{4}{*}{0.423} \\
\hline & $<-$ anthropcentrism & 0.379 & 7.595 & .000 & 0.420 & \\
\hline & $<-$ altruism & 0.221 & 3.947 & .000 & 0.228 & \\
\hline & $<--$ egoism & -0.072 & -1.721 & $.085 *$ & -0.074 & \\
\hline $\begin{array}{l}\text { Attribution of } \\
\text { responsibility (AR) }\end{array}$ & $<-\mathrm{AC}$ & 0.465 & 12.198 & .000 & 0.584 & 0.341 \\
\hline \multirow{5}{*}{$\begin{array}{l}\text { Personal } \\
(\mathrm{PN})\end{array}$} & $<-\mathrm{AR}$ & 0.240 & 5.258 & .000 & 0.214 & \multirow{5}{*}{0.645} \\
\hline & $<--$ ecocentrism & 0.007 & 0.266 & $.791 \%$ & 0.008 & \\
\hline & $<-$ altruism & 0.270 & 6.130 & .000 & 0.311 & \\
\hline & <-- egoism & -0.034 & -1.093 & $.274 *$ & -0.039 & \\
\hline & $\begin{array}{l}\text { PN }<-- \\
\text { anthropocentrism }\end{array}$ & 0.189 & 4.777 & .000 & 0.233 & \\
\hline $\begin{array}{l}\text { Energy } \\
\text { conservation }\end{array}$ & \begin{tabular}{|ll}
$\begin{array}{l}\text { Energy } \\
\text { conservation }\end{array}$ & $<-$ PN \\
\end{tabular} & 0.262 & 5.760 & .000 & 0.241 & 0.058 \\
\hline
\end{tabular}

(*) non-significant relationship

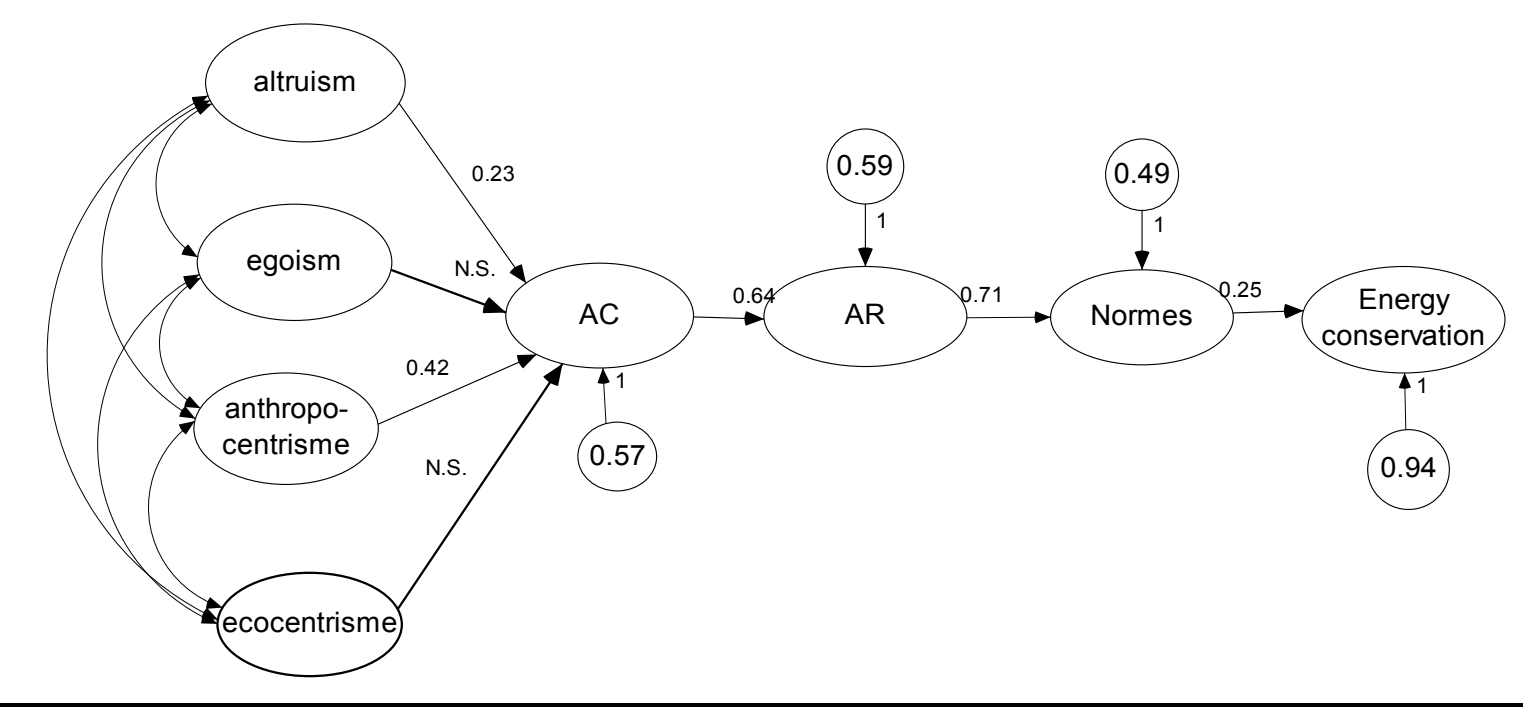

Figure 1. Th structural model of the VBN 